\title{
Um encontro de monarcas, de Selma Lagerlöf
}

\author{
Carlos Rabelo ${ }^{1}$
}

\section{Introdução}

Selma Lagerlöf (1858-1940) é uma das maiores figuras da Literatura Sueca, sendo a primeira escritora a receber o Prêmio Nobel, em 1909, e uma escritora cuja prosa é bastante lida e traduzida até hoje. Seu prestígio na Suécia é tão grande que sua imagem aparece nas cédulas de vinte coroas. Seus temas e seu estilo literário carregam um sabor marcadamente nacional, com personagens regionais e com influência da literatura folclórica. Como se nota neste conto, ela é uma excelente contadora de histórias, com forte senso de humor e aguda percepção sobre o mundo e as pessoas. Foi uma especialista na forma da saga, o conto popular escandinavo, e alguns de seus livros são clássicos da literatura infantojuvenil, como é o caso do romance $A$ Viagem Maravilhosa de Nils Holgersson através da Suécia, editado no Brasil pela Editora Nórdica, com tradução de Manoel Paulo Ferreira. Nesse romance, quase uma rapsódia sueca, um menino é encolhido e sobrevoa a Suécia nas asas de um bando de gansos selvagens.

O conto que aqui apresentamos, "Um encontro de monarcas" ("Monarkmötet"), faz parte uma antologia intitulada Troll och människor ("Trolls e e pessoas"), publicado em 1915. É importante ter essa data em mente para compreender o sentido do conto, que se refere ao começo da Primeira Guerra Mundial em 1914. Com grande capacidade de atenção ao que se passava em seu tempo, a autora, ao descrever um episódio local, com seu humor camponês, conseguiu farejar os ventos

1 Carlos Rabelo é dramaturgo, tradutor do sueco e doutorando em Artes Cênicas no PPGAC (Programa de Pós-Graduação em Artes Cênicas) da UFBA (Universidade Federal da Bahia). 
da tragédia militar que se abateria sobre o mundo no século XX. É um exemplo da capacidade de artistas de serem universais ao representarem suas aldeias, sejam estas em Goiás ou em Värmland, a província natal de Lagerlöf.

Para marcar sua posição contrária à guerra, cuja sombra já pairava sobre a Europa, a autora conta um episódio fictício, onde imagina o encontro de uma figura histórica com um personagem fictício que figura em um de seus romances. A figura histórica é o rei Oskar II da Suécia, último rei sueco da Noruega, que reinou sobre a transição pacífica graças à qual a Noruega tornou-se independente da Suécia em 1907. Como podemos ler nesse conto, a pressão de nacionalistas suecos era no sentido de manter a Noruega como parte da Suécia, mesmo que com o uso da força. E este rei, mantendo a tradição que se iniciara com a dinastia Bernadotte, usou de seu prestígio pessoal para defender a paz. Ou seja: foi um dos arquitetos de uma Escandinávia evoluída socialmente, sem grande traumas históricos nos séculos recentes.

Já o personagem fictício, Jan, é o herói de um romance de Lagerlöf intitulado O imperador de Portugália (Kejsarn av Portugallien), publicado em 1914, onde um camponês com delírios de grandeza se imagina o imperador de um país fantástico e mediterrâneo, "Portugália", que reflete bem o sonho no Sul ensolarado, com terras propícias ao vinho e à felicidade, longe do frio severo e da escuridão da Escandinávia. Nesse romance, que foi editado em Portugal em 2006, com tradução de Esther de Lemos, Lagerlöf discute o desespero da pobreza, a ignorância, que se converte numa autoilusão, de um personagem perdido em seus sonhos de grandeza.

Desse modo, no conto que aqui apresento, Lagerlöf propõe um embate entre ficção e realidade, sendo que seus dois reis simbolizam o encontro da razão e da verdade com a loucura e a mentira. E, sabiamente, Lagerlöf mostra como a verdade, representada pela figura do rei Oskar, aprende com o comportamento da mentira, corporificada por Jan. A simpatia do leitor também fica do lado da mentira, das extravagâncias do camponês Jan, um pícaro que põe em cena a imagem do ser humano confuso, perdido em meio à complexidade do mundo. Daí a importância de estadistas comprometidos com a paz, como Lagerlöf descreve o monarca verdadeiro, o rei Oskar, que preferiu perder um país inteiro, a Noruega, do que subjugá-lo à força para manter o brilho de sua coroa.

Nessa tradução busquei reproduzir em português a leveza do estilo de Lagerlöf, a coloquialidade e seu senso de humor. Jan, o personagem camponês, fala em dialeto de Värmland, e seria possível fazer com que ele falasse em nosso dialeto caipira - no entanto, essa escolha levaria a imaginação do leitor em direção a outro mundo e outra geografia. Outro traço do estilo da autora é o tom de quem 
conversa com as pessoas, como quem conta uma história ao redor da lareira. Daí também a brevidade do conto, e suas descrições sumárias e precisas. Trata-se quase de uma anedota expandida, que narra um encontro onde as regras sociais foram postas de lado numa sociedade tão formal quanto a sueca, o que se torna ainda mais notável por envolver a presença de um rei e de um excêntrico que se julga rei. Espero que mais obras de Selma Lagerlöf sejam traduzidas e editadas no Brasil, para que tenhamos o prazer de ler sua prosa tão humana e universal. 


\section{Monarkmötet}

\section{Selma Lagerlöf}

Det var i början av åttitalet vid en järnvägstation i Värmland, där kungen skulle resa förbi. Man hade klätt med grönt och med blommor, det svajade fanor i luften, och allt folk, som fanns i hela trakten, hade strömmat dit.

Och medan människorna väntade på att kungatåget skulle komma, var de både glada och lyckliga. De stod och gjorde upp för sig hur de skulle ta emot majestätet. De skulle ropa hurra, och de skulle ge honom blommor, och de skulle sjunga. Ja, här vid Kils station skulle han bli så mottagen, att han aldrig skulle förglömma det.

Men när tåget brusade in på stationen, blev det en stor oro strax i början, därför att alla ville tränga sig fram, så att de skulle komma i närheten av kungens vagn. Det var ju nu, som de skulle ha ropat hurra, men det glömde de rent bort, av ängslan för att de inte skulle kunna armbåga sig fram till någon bra plats.

Men en var det, som varken sprang eller trängdes, utan bara stod stilla och höjde käppen med den stora silverknappen för att slå takt, och som hurrade så, att det genljöd i alla väggar. Det var en liten karl, som hade en hög, grön kaskett på huvudet och hela bröstet fullsatt med stjärnor av både guld- och silverpapper.

Och det kan nog hända, att kungen och de, som var med honom, lade märke till att det fanns en karl i hela hopen, som var lugn och bar sig rätt åt, när alla de andra var som stolliga.

Inte blev det något av med sången, för se, skolbarnen, som skulle sjunga, de hade i trängseln blivit förskingrade åt alla håll, och inte heller fick kungen några blommor. De, som stod med buketter i händerna, hade blivit så förstenade av blyghet, att de inte kom sig för att gå fram till honom.

Det var bara en karl, som inte förlorade besinningen, och just i detsamma som kungen kom ut ur järnvägsvagnen och steg ner på träbron framför stationshuset och stod där och såg både bekymrad och ledsen ut, därför att han hade fått ett så dåligt mottagande, så banade sig den karlen väg fram till honom.

»Go’dag, min snälla Oskar den andre!» sa karlen, och därmed tog han av sig kasketten och sträckte fram handen.

Kungen såg riktigt belåten ut. Han blev nog glad över att här vid Kils station fanns någon, som inte var blyg och inte hade blivit yr i mössan, utan visste hur han skulle bete sig.

»Go’dag, du!» sa kungen tillbaka. »Vad är du för en?» 
Då svarade karlen, som sanningen var: »Jag är kejsar Johannes av Portugallien.» Men han sade det med en så mild och len röst, som det var honom möjligt, för det kunde ju hända, att kungen var van att alltid vara den första här i landet, och att han inte skulle tycka om, att det fanns en, som stod lika högt som han.

Det var nog flera, som var rädda för att det kunde förhålla sig så, för de, som stod närmast, ryckte honom i rocken och ville ha bort honom, liksom om de inte var säkra på hur detta mötet skulle sluta. Men kungen var inte av det slaget, som inte kan tåla sin like. Han bara vinkade åt dem, att de skulle hålla sig stilla.

»Kors i alla mina dar!» sa han och lät riktigt glad i rösten. »Är det en ämbetsbroder, som jag har råkat ut för?»

»Ja, vi har väl ungefär samma börda te å bära,» sa då han, som var kejsare, så ödmjukt, så. För se, att skryta över att han hade ett högre ämbete, han, än den andre, det skulle han aldrig ha kunnat förmå sig till att göra.

»ag hör, att du har den rätta uppfattningen av saken,» sa kungen. »De, som inte har prövat på vad det vill säga, de tror, att vi kungar inte har något annat att göra än att sitta på en tron med krona på huvudet och spira i handen. Men bli kung bara, så får man se på annat. Tänk, att det ska kännas tungt också till att vara kejsare av Portugallien!» lade han till med en suck.

»Det har ju inte var’t så värst tungt hittills,» sa då kejsarn, för han ville förstås inte skämma ut det egna landet. »Vi har ju fått behålla freden, och det är ändå det förnämsta goda.»

Det syntes allt, att kungen blev storbelåten.

»Det är inte fritt, att inte du förstår dej på regeringskonsten,» sa han. »För se, att hålla fred, det är både det första å det sista. Freden är för riket detsamma, som hälsan är för kroppen.»

Kejsarn fick allt lov att vända sig om och se sig omkring, när kungen sade detta. Folk stod molstilla i en vid krets, och inte en enda tordes röra sig ur fläcken bara för att inte mista ett ord av det, som han och kungen sade till varandra. Det hade allt varit bra, om han hade tänkt på att ta Kattrinna med sig. Åtminstone skulle han ha önskat, att någon enda Svartsjöbo, och helst någon av herrkarlarna, hade varit tillstädes.

Men på samma gång hörde han noga efter vad kungen sade och var strax färdig att svara honom.

»a, nog är freden e god sak,» sa han.

»Men en kan inte veta hur länge vi får behålla honom, för i söndags, när jag skulle gå hem från gudstjänsten i Svartsjö kyrka, kom jag i sällskap med två främmande karlar. A den ena åv dom var Kriget, å den andra var Döden.»

Det var så vanligt för honom, som var kejsare av Portugallien, att råka alla slags konstigheter och besynnerligheter, så att inte hade han trott på att det, som han berättade om mötet på kyrkvägen, skulle bli betraktat som något försök att förhäva sig. Men det 
måtte det ändå ha blivit, för nu började de på att rycka honom i rocken igen, de, som stod bakom, och ville ha honom att tiga. Men kungen förstod nog, att ett sådant där möte, det var som ingenting att räkna för en sådan som han, och han vinkade åt folket, att de skulle hålla sig stilla.

»Vad är det du säjer?» sa han. »Har du varit ute å gått i sällskap med Döden å Kriget? Jag kan just undra hur de två såg ut.»

»Di var väl mest lika ett par fattiga vedhuggare,» sa kejsarn, »för di gick med stora timmeryxor på axeln. När jag hade fått veta vilka di var, så fråga' jag dom förstås vad di var ute i för ett ärende, å då sa di, att di gick omkring å drog ihop bränsle te stora bål. Di vandra' från land te land, sa di, å bara di blev färdiga, så skulle di sätta eld på hela världen.»

»De kunde väl aldrig tänka på att lägga opp något bål i det här landet heller,» sa kungen, och alltjämt smålog han och såg glad ut.

»Di trodde allt, att det skulle bli klent med förtjänsten här i landet,» sa kejsarn. »Men di skulle ändå göra ett försök på västkanten. För där trodde di att det var möjligt, att di kunde samla ihop bränsle te ett ordentligt bål.»

Men tänk, att med detsamma som kejsarn hade talat om västkanten, så rätade kungen upp sig och blev allvarsam. »Nej,» sa han helt tvärt och höjde rösten, så att det han sade kunde höras till varenda människa på Kils station, »det kommer inte att lyckas för dem. Det kommer inte att bli något arbete för Krig å Död åt det hållet, så länge jag lever. För tror du, att jag vill vara kung över folk, som jag skulle vara tvungen att underlägga mej med makt å våld? Jag vet väl, att det är svårt att hålla fred, men hellre vill jag offra kronan, än att jag skulle släppa lös eld å plundring över fredliga städer å byar å se åkrar nedtrampade å se människor döda å lemlästade. Jag har sett hur det har gått framåt i mina två länder under min regering,» sa han och kastade en stor, ljus blick omkring sig, »å aldrig ska jag vara med om att förstöra det, som det har varit min största glädje att se växa.»

När kungen hade sagt detta, hade han fått glans över ansiktet, och rösten skälvde till så vackert, att man hörde, att han menade vad han sade. Men kejsarn hade ju aldrig väntat mindre av honom, och nu lade han handen på armen på honom. »Min snälla kung Oskar! Min snälla kung Oskar!» sa han för att lugna honom.

»Ja, sätt mej på prov bara!» sa kungen och såg än stoltare ut än förut.

Men folket runt omkring tyckte, att kungen talade så vackert, att de fick tårar i ögonen, och rätt som det var, var det en, som gav sig till att ropa hurra.

Med detsamma tog de upp ropet över hela Kils station, och nu viftade de åt honom med hattar och näsdukar, och nu sjöng de, och nu kom de med blommor, för se, nu var de inte rädda för honom mer, nu hade han värmt dem. Nu fick han allt det, som de inte hade kommit sig för med att ge honom, då de först såg honom.

Men medan kungen av Sverige blev hyllad och firad, stod kejsarn av Portugallien alldeles stilla en stund och såg på med stora ögon. Sedan smög han sig så stilla och tyst bort genom folkhopen. 
Inte för att han kände sig på minsta sätt missbelåten med att han hade fått göra bekantskap med en riktig kung, men nog tycktes det, att han såg bra fattig och liten och avsigkommen ut, när han gav sig i väg hem till Svartsjösocknen.

Det var mången, som gladde sig åt kungens ord vid Kils station, men just ingen trodde då, att man fick ta dem alldeles efter bokstaven.

Sedan, flera år efteråt, då man såg hur det gick, var det flera, som påminde sig samtalet, och då förstod de, att kungen hade sagt sant, och att han hade bestått provet.

Och att det var sant med dem, som gick omkring och samlade ihop bränsle till världskriget, det har vi också sett.

Men när visar sig för oss den store fridsfurste, som inte kan se människor lida och byar brännas och åkrar nedtrampas? När kommer han, som vill offra kronans ära och glans för att ge den förtvivlade världen fred? 


\title{
Um encontro de monarcas
}

\author{
Selma Lagerlöf \\ Tradução do sueco: \\ Carlos Rabelo
}

Foi no começo dos anos de 1880, numa estação de trem em Värmland, por onde o rei viria de passagem. Revestiram a estação com buquês de flores, bandeiras tremulavam ao vento e todo o povo da região vinha em revoada.

As pessoas aguardavam felizes e alegres a chegada do trem real. Imaginavam como iriam saudar Sua Majestade. Gritariam “viva!”, oferecer-lhe-iam flores e cantariam. Realmente, na estação de Kil ele seria bem recebido, para nunca mais esquecer.

Mas quando o trem encostou na estação, uma grande desordem se instalou, porque todos se empurraram, tentando chegar mais perto do vagão do Rei. Era nesse momento que deviam gritar "viva!", mas todos se esqueceram completamente devido ao receio de não conseguir se acotovelar cada vez mais para a frente, até conseguir um bom lugar.

Porém, teve alguém que nem correu, nem se espremeu, mas ficou parado, levantou a bengala de cabo de prata, para marcar o ritmo, e bradou "viva!" com tanta força que se ouviu através de todos os vagões. Era um sujeito pequeno, que portava uma cartola alta e verde; tinha o peito coberto de estrelas de papel dourado e prateado.

$\mathrm{E}$, como era de se esperar, o rei e aqueles que estavam com ele repararam que havia um sujeito no meio da algazarra que estava calmo e que se portava bem, enquanto todos os outros pareciam estúpidos.

Nem houve canção nenhuma, pois vejam, as crianças que deviam cantar tinham se dispersado na confusão, e também o Rei não recebeu nada de flores. Aqueles que estavam segurando os buquês, petrificados de timidez, não tinham coragem de ir até ele.

Só aquele homem não perdeu a compostura, e assim que o Rei deixou o vagão, descendo até a ponte de madeira, em frente à estação, com o cenho preocupado e triste por ter sido tão mal-recebido, o sujeito se dirigiu até ele:

- Bom dia, meu querido Oscar II! - disse ele, tirando a cartola da cabeça e estendendo a mão.

O rei ficou bastante satisfeito. E ficou feliz em saber que em Kil havia alguém que não era tímido, que não perdia a cabeça e sabia como se portar.

- Bom dia, meu caro! - respondeu o rei. - E quem é você?

Ao que o homem respondeu, com convicção: 
- Sou o imperador João de Portugália -- disse ele com sua voz mais suave e doce, pois poderia ser que o rei estivesse acostumado a sempre ser a pessoa mais importante do país, talvez não gostando que houvesse alguém em posição tão alta quanto a dele.

Muitos ficaram preocupados com o que se poderia seguir àquela situação, e assim aqueles que estavam mais perto tentaram puxar o paletó do homem, querendo tirá-lo dali, não estando seguros de como aquele encontro poderia terminar. O rei, no entanto, não era do tipo de gente que não tolera um semelhante. Ele apenas fez um gesto aos demais, para que ficassem em seu lugar.

- Meu Deus Todo-Poderoso! - disse ele com alegria na voz. - Será que eu me deparei com um colega de profissão?

- Sim, nós temos mais ou menos o mesmo fardo nas costas - disse então ele, que era imperador, mui humildemente. Pois vejam, vangloriar-se de que tinha uma posição superior ao do outro era algo que jamais se permitiria fazer.

- Noto que tem o entendimento correto dessa questão - disse o rei. - Aqueles que não tiveram a experiência do que isso significa acreditam que nós, os reis, não fazemos mais que sentar no trono com a coroa na cabeça e o cetro na mão. Mas quando se é rei, vê-se de outro modo. Imagine o peso que se sente quando se é imperador de Portugália! - completou ele, com um suspiro.

- Não tem sido tão ruim até agora - disse então o imperador, não querendo obviamente envergonhar seu país. - Nós conseguimos manter a paz, que é o bem mais precioso.

Todos puderam ver que o rei ficou contentíssimo.

- Ninguém poderá dizer que não entende da arte de reinar - disse ele. - Pois vejam, manter a paz deve ser a nossa primeira e última preocupação. A paz é para o reino o mesmo que a saúde é para o corpo.

O imperador teve a oportunidade de se virar e olhar em volta enquanto o rei dizia isso. As pessoas estavam como que fincadas ao chão, em um largo círculo, e ninguém sequer ousava se mexer do lugar, para não perder uma palavra do que ele e o rei estavam dizendo. Seria melhor ainda se ele tivesse pensado em trazer sua esposa Katrina ${ }^{2}$. Ao menos ele gostaria que algum morador de Svartsjö, especialmente alguém da nobreza, tivesse consentido em vir.

Mas ao mesmo tempo ele escutava cuidadosamente o que o rei dizia, estando pronto para respondê-lo de imediato.

- Sim, a paz é realmente uma coisa muito boa - disse ele. - Mas a gente não sabe até quando vai poder mantê-la, porque no domingo, quando eu voltava pra casa, vindo do culto na igreja de Svartsjö, me vi na companhia de dois senhores de fora. Um deles era Guerrra, e o outro era Morte.

2 A esposa de Jan, e personagem do romance O imperador de Portugália. 
Era tão comum para ele, que era imperador de Portugália, se deparar com todo tipo de estranhezas e singularidades, que jamais imaginaria que aquilo que contou acerca do encontro no caminho da igreja seria considerado uma tentativa de se engrandecer. Mas pode ter sido o que aconteceu, já que as pessoas ao redor começaram novamente a puxá-lo pelo paletó, no intuito de que se calasse. O rei, no entanto, entendia que um encontro de tal sorte era o mesmo que nada para alguém como ele, e conteve as pessoas com um gesto.

- O que está dizendo? - disse ele. - Esteve por aí em companhia do Sr. Morte e do Sr. Guerra? Só posso imaginar qual era a aparência dos dois.

- Pareciam assim dois lenhadores pobres - disse o imperador. - Pois cada um trazia um grande machado no ombro. Quando pude saber quem os dois eram, perguntei, é claro, por que estavam de saída, e eles disseram que estavam juntando lenha para fazer uma fogueira. Eles vagueiam de terra em terra, disseram, e assim que estivessem prontos ateariam fogo ao mundo inteiro.

- Eles jamais deveriam pensar em atear fogo nessa terra - disse o rei, com um leve sorriso e aparência benévola.

- Os dois acreditam que por essas partes haveria pouco trabalho - disse o imperador. - Mas, assim mesmo, fariam uma tentativa na fronteira Oeste ${ }^{3}$. Lá eles pensam que é possível conseguir juntar lenha bastante para uma senhora fogueira.

Imaginem só, assim que o imperador falou sobre a fronteira Oeste, o rei se endireitou e ficou sério:

- Não - disse ele abruptamente, e elevando a voz, para que cada pessoa da estação de Kil ouvisse. - Eles não vão conseguir. Não haverá nenhum trabalho para Guerra ou Morte desse lado da fronteira enquanto eu estiver vivo. Você pensa que eu quero ser rei de um povo que eu seria obrigado a subjugar com força e violência? Sei bem que é difícil manter a paz, mas antes sacrificar a coroa do que ver o fogo e a pilhagem se alastrando por cidades e vilas pacíficas, plantações arrasadas, pessoas mortas ou mutiladas. Eu pude ver a evolução que se passou nos meus dois países, sob o meu reinado - disse ele, lançando um olhar amplo e claro ao seu redor -, e jamais vou fazer parte de algo que destrua aquilo que foi a minha maior alegria ver crescer.

Quando o rei disse isso, seu rosto se iluminou, e sua voz vibrou com tanta beleza que se podia escutar que falava com sinceridade. Mas o imperador esperava mais dele, e pôs a mão em seu braço:

- Rei Oscar, por favor! Por favor, Rei Oscar! - disse ele, procurando acalmá-lo.

- Que me ponham à prova! - disse o rei, com mais orgulho do que antes.

$\mathrm{E}$ as pessoas ao redor sentiram que o rei falara com tanta beleza que ficaram com lágrimas nos olhos, e como o momento era apropriado, teve alguém que não se conteve e gritou "viva!".

3 Em referência à Noruega. 
E num instante a gritaria tomou conta da estação de Kil, e foi então que sacudiram os lenços e os chapéus, foi então que cantaram, foi então que lhe entregaram as flores, pois vejam, já não tinham medo dele, que tinha conseguido quebrar o gelo. E assim ele recebeu tudo que não haviam lhe dado antes, quando o viram pela primeira vez.

Mas enquanto o rei da Suécia era celebrado e saudado, o imperador de Portugália permaneceu totalmente parado, de olhos arregalados. Em seguida saiu de fininho, sem dizer nada, silencioso por entre as pessoas.

Não porque ele se sentisse insatisfeito por ter travado conhecimento com um rei de verdade, mas assim mesmo ele sentiu-se bem pobre, pequeno e desanimado ao andar pela estrada que conduzia à sua casa na vila de Svartsjö.

Houve muitos que se alegraram com as palavras do rei na estação de Kil, porém ninguém acreditou realmente naquele dia que se podia tomá-las ao pé da letra.

Depois de muitos anos, quando se soube o que aconteceu, muitas pessoas que se recordavam daquela conversa compreenderam que o rei dissera a verdade e que havia passado na prova.

E que era verdade que aqueles dois que andavam ao redor, juntando lenha para a guerra mundial, também vimos.

Mas quando veremos o grande príncipe da paz, que não consegue ver as pessoas sofrendo, cidades ardendo, e lavouras arrasadas? Quando ele virá, aquele que oferecerá a glória e o brilho da coroa para dar a este mundo louco a paz? 